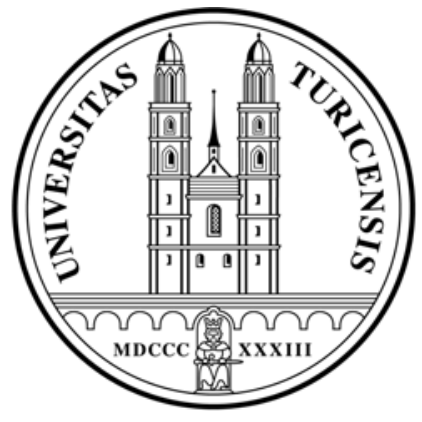

Institute for Empirical Research in Economics

University of Zurich

Working Paper Series

ISSN 1424-0459

Working Paper No. 460

Of Bubbles and Bankers:

The Impact of Financial Booms on Labor Markets

Tobias Wuergler

December 2009 


\title{
Of Bubbles and Bankers: \\ The Impact of Financial Booms on Labor Markets
}

\author{
Tobias Wuergler, University of Zurich*†
}

December 16, 2009

\begin{abstract}
This paper studies the effect of financial booms and extreme asset valuations on the relative demand for skills and the wage structure. The substantial rise in wage inequality in the U.S. since the late 1970s has been accompanied by a major expansion of financial services, a series of asset bubbles, and rising relative wages and relative education in the financial industry. I motivate and develop a theoretical framework where financial institutions benefit from financial booms and asset bubbles. Yet the complexity and novelty of financial products and fundamentals surrounding bubbles favor the supremacy of skilled individuals in exploiting these opportunities. Hence financial booms increase opportunities for skilled labor, contributing to the rise in overall wage inequality in the economy. Simple extensions of the basic framework allow us to study the implications of financial regulation and globalization of financial services, as well as further topics. Finally, the paper documents and compares relative wage and employment patterns in the U.S., U.K., Germany, and France, providing suggestive evidence for the theoretical framework.
\end{abstract}

JEL classification: E24, E44, G20, G28, J24, J31

Keywords: Skill demand, inequality, asset bubbles, financial institutions, financial regulation

${ }^{*}$ University of Zurich, Institute for Empirical Research in Economics, Muehlebachstrasse 86, CH-8008 Zürich, e-mail: wuergler@iew.uzh.ch, phone: +41 764133213

${ }^{\dagger}$ I thank Philippe Aghion, Pol Antras, Reto Foellmi, Christian Hepenstrick, Reto Foellmi, Rafael Lalive, Manuel Oechslin, Ariell Reshef, Fabrizio Zilibotti, Josef Zweimueller, and seminar participants at the ECB/CEPR Labour Market Workshop in Frankfurt for valuable discussion, as well as Yanik Sterchi for excellent research assistance in the empirical part. 
"The measure of success attained by Wall Street, regarded as an institution of which the proper social purpose is to direct new investment into the most profitable channels in terms of future yield, cannot be claimed as one of the outstanding triumphs of laissez-faire capitalism - which is not surprising, if I am right in thinking that the best brains of Wall Street have been in fact directed towards a different object."

John Maynard Keynes, The General Theory of Employment, Interest and Money (1936)

\section{Introduction}

The substantial rise in wage inequality in the U.S. since the late 1970s documented in many studies (e.g. Katz and Autor, 1999; Piketty and Saez, 2003) has been accompanied by a major expansion of the financial industry, and a series of asset bubbles including the LBO boom of the 1980s, the dot-com bubble of the 1990s, and the recent credit and housing boom. While the U.K. has experienced a similar surge in inequality, major Continental European economies such as France have not (Katz and Autor, 1999; Piketty, 2007). Given the prominent role of Wall Street and the City of London in the financial booms of the past decades, one wonders whether the financial sector and asset bubbles have been contributing factors to the divergent paths of wage inequality.

Figure 1a illustrates the strong expansion of the financial industry in the U.S. and U.K. over the past decades. Since the late 1970s - around the time of the financial deregulations of Reagan and Thatcher - the shares of financial intermediation in U.S. and U.K. GDP have risen substantially, while no such trend can be discerned in Continental European economies such as France and Germany. And indeed, the expansion of the financial sector has been accompanied by a substantial rise in wage premia earned in finance compared to non-finance jobs in the U.S. and in the U.K, while these wage gaps have been stagnating or even slightly receding in France and Germany. ${ }^{1}$

Motivated by these patterns, the present paper takes the viewpoint that modern financial markets have been characterized by an ever-increasing number of new financial structures and recurring phases of extreme asset valuations; which resulted in high fees and increasing rents to be earned in the financial sector; and that these features have played an important role in the

\footnotetext{
${ }^{1}$ The finance/non-finance wage gaps are calculated using standard wage regressions including the usual controls, see empirical section. Given the differences in data sets across countries, differences in levels should not be overemphasized, and the present analysis focuses on trends.
} 


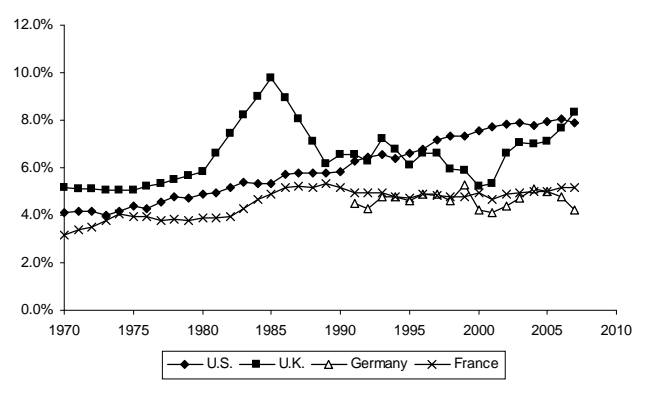

a) Share of financial intermediation in GDP

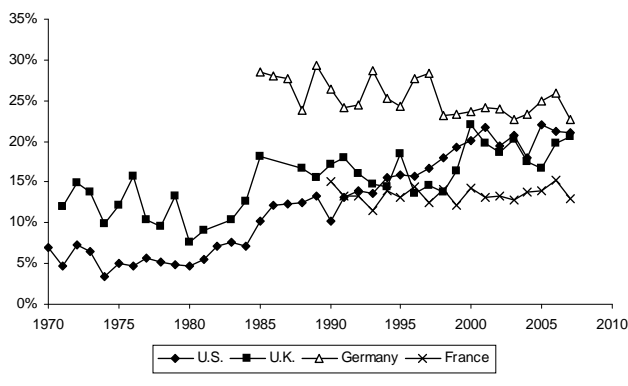

b) Finance/non-finance wage gap

Figure 1: Financial sector developments (Source: a) Gross Value Added; U.S. Industry Accounts, U.K. National Accounts, INSEE/Comptes Nationaux, Eurostat; b) Wage regressions; CPS, BHPS, GHS, SOEF, LFS)

developments of the international wage structure. The paper develops a theory where financial institutions benefit from deregulations and extreme asset valuations. Yet the complexity and novelty of financial products and fundamentals surrounding asset bubbles favor the supremacy of certain groups of workers such as the higher-skilled in exploiting these opportunities. Hence financial booms increase opportunities for skilled workers in financial services, contributing to the rise in overall wage inequality. Simple extensions of the basic framework allow us to study the role of financial regulation, the consequences of globalization of financial services, and potential drivers of the wage gaps between finance and non-finance jobs. The second part of the paper investigates the implications of the model using wage data of advanced OECD countries including the U.S., U.K., Germany, and France.

The basic framework is based on a simple overlapping generations economy with three key ingredients: First, asset bubbles may arise under certain economic conditions. Second, workers differ in their skill sets (e.g. educational levels, and in an extension, in other characteristics). Third and most importantly, deregulation and asset bubbles create rent opportunities in the financial sector. The savings and investment process of the economy is organized around financial intermediaries, which engage in traditional intermediation, collecting savings from households and lending them to the real production sector. Traditional intermediation is essential for the capital accumulation of the economy but can be standardized to a high degree and consequently yields low fees. Savings can also be channeled into new financial structures and asset bubbles. The key assumptions is that this intermediation of bubbles generates high fees and is relatively skill-intensive given the complex nature of new financial products and fundamentals surrounding asset bubbles.

The analysis shows that deregulation and the emergence of asset bubbles leads to a growing 
financial sector, higher employment of skilled individuals in the financial sector, and higher wage inequality between more-skilled and less-skilled individuals. As more rent opportunities arise for skilled individuals, the financial sector absorbs a growing mass of skilled workers, inflating the sector, while lowering real output. The scarcity of skilled individuals in real production drives up their marginal products and wages in the economy.

The framework is used to evaluate the impact of financial regulation policy. It can be shown that stricter regulation of traditional intermediation makes conditions for bubbles less likely, but more importantly, hurts the real sector by lowering the range of capital goods intermediated. On the other hand, stricter regulation of bubble intermediation mitigates the negative effect of rent seeking activities on real output and inequality. A simple two-country extension of the basic model allows us to study the impact of globalization of financial markets and services. It can be demonstrated that the country with looser regulation evolves into the leading financial center, plagued by higher inequality. Furthermore, increasing returns to scale in intermediation due to local spillovers can turn the effect of initial loose regulation persistent across time. These findings will be important when evaluating wage and employment data across financially integrated countries such as within Europe. Finally, another simple extension demonstrates how differences in access to rents and in tastes generate growing wage gaps between between finance and non-finance jobs in periods of deregulation and inflating bubbles.

The results are in line with a recent empirical study by Philippon and Reshef (2008). Using wage and employment data for the U.S., they document that "financial jobs were relatively skill intensive, complex, and highly paid until the 1930s and after the 1980s, but not in the interim period." Initial calculations of the authors revealed that the financial sector contributed about $15-20 \%$ to the rise in overall wage inequality in the U.S., thus being an important contributing factor. $^{2}$ The model of this paper is consistent with these findings as both episodes before the 1930s as well as after the 1980s were marked by significant asset bubbles and light regulation. Another recent study also finds that financial development increases inequality, while banking crises reduce top income shares of the rich, using a panel of 16 countries over the twentieth century (Roine, Vlachos, and Waldenström, 2009).

The second part of the paper extends the still small empirical literature on inequality and the financial sector by evaluating wage and employment data of the four largest advanced OECD countries with comparable household survey data available: the U.S., U.K., Germany, and France. The aim is to document and compare wage and employment patterns over the last decades, providing suggestive evidence for the theoretical framework. The U.S. and U.K. spearheaded the global deregulation of financial markets and services starting in the 1970s,

\footnotetext{
${ }^{2}$ Presentation at the NBER Summer Institute 2009 of Reshef
} 
which accelerated substantially in the 1980s under Reagan and Thatcher. Germany and France eventually followed but at a slower pace. As a result of these and other factors, the U.S. and U.K. could build comparative advantages in intermediation translating into higher financial activities than in Germany and France. Motivated by these observations, wage and employment structures in the financial sector are studied, contrasting the Anglo-Saxon with the Continental European experience over the past decades. Finally, general trends in wage inequality are compared across countries with special attention turned to the timing of deregulation and the rise of asset bubbles.

Besides the extension of the empirical literature on inequality and financial services, the paper contributes to the extensive literature on the documentation and causes of the rise in wage inequality (e.g. educational wage differentials) in the U.S. Leading explanations include directed (skill-biased) technical change (e.g. Autor, Katz, and Krueger, 1998; Acemoglu, 1998 and 2002; Acemoglu and Zilibotti, 2001), the decline in union activity (e.g. DiNardo, Fortin, and Lemieux, 1996; Card, 1998), and globalization/outsourcing (e.g. Feenstra and Hanson, 1996). This paper highlights the role of asset bubbles and financial deregulation as important contributing factors to the rise in wage inequality in the U.S. and U.K., and the divergence from Continental Europe.

And finally, the paper is related to the theoretical literature on the impact of financial services on the economy. One strand of theoretical work has stressed the growth promoting effect of financial intermediation (e.g. Greenwood and Jovanovic, 1990; Bencivenga and Smith, 1991). On the other hand, Murphy, Shleifer, and Vishny (1991) make the example of trading as a rent seeking activity with negative effects on growth. The present paper evaluates both aspects of the financial sector in a single framework: It introduces a simple yet intuitive structure to study traditional intermediation in a macroeconomic context, modelling banks as monopolistic competitive lenders specialized in different real sectors. And it formalizes rentseeking intermediation with bubbles and loose regulation as sources of rent opportunities in the financial sector. Independently of this work, Cahuc and Challe (2009) have developed a similar theoretical framework studying the effects of asset bubbles on occupational choice in the presence of financial intermediaries yielding similar results.

The paper is organized as follows. Section 2 motivates the key assumptions and mechanisms, and provides an overview of the main findings. Section 3 introduces the theoretical framework. It then derives and analyzes the equilibrium and conditions for bubbles. Finally, the main results of the model are presented, studying the impact of asset bubbles on labor markets, the role of financial regulation, globalization of financial services, and finance/nonfinance wage gaps. Section 4 documents and compares wage and employment patterns of the U.S., Germany, U.K., and France, providing suggestive evidence for the theoretical framework. 
Section 5 concludes.

\section{Financial sector, bubbles, and labor markets: an overview}

Financial institutions engage in financial intermediation, around which the savings and investment process of the economy is organized. Intermediaries serve the business sector, supplying it with capital; and they serve households, investing their savings. In an economy free of asset bubbles and speculative excesses, financial institutions channel the households' savings mainly into businesses. They identify, finance and monitor entrepreneurs, start-ups as well as mature businesses, and then transform duration, risk and lot sizes of these investments, in order to create suitable savings vehicles for households. This "traditional intermediation" is a crucial element of the capital accumulation and innovation process of an economy.

By channeling savings into investments, however, financial institutions are often substantially involved in the creation and inflation of speculative manias and asset bubbles, i.e. in the "intermediation of bubbles". They trade bubbly assets on behalf of clients, create and manage new structures and products, and expand bank credit for clients to invest in the latest trends (see Kindleberger, 1996). Investors are willing to pay high fees in order to participate in the latest financial innovations and investment trends expected to generate more stable or higher returns than traditional investments. And the proprietary trading units of banks and hedge funds can profit from these frenzies by acting as counterparties, often both on the up- and downside. In fact, financial institutions have every incentive to propagate these products and bubbles as they are able to benefit handsomely. The share of the financial sector in U.S. GDP has risen strongly during the stock market boom of the 1920s and since the 1980s, whereas the share collapsed during the Great Depression and WWII (see Philippon, 2008).

According to Minsky and Kindleberger, speculative booms start with a displacement such as the widespread adoption of an invention with pervasive effects, e.g. canals, railroads or the automobile. Newer treatments of asset bubbles, such as Shiller (2000), Abreu and Brunnermeier (2003), and Caballero, Fahri and Hammour (2006) also emphasize the importance of productivity enhancing structural change for the emergence of bubbles. And Blanchard and Watson (1982) argue that bubbles are more likely where fundamentals are difficult to assess. In the late 1920s, major industrial changes were under way, which made fundamentals difficult to assess and forecast, such as the shift from Ford to GM or the emergence of high-tech firms and utilities with no dividend histories. These stocks became the favorites in the resulting stock market boom (White, 1990). And the more recent bubbles were driven by the internet and telecommunication boom, and subsequently by new funding and risk management techniques such as securitizations fueling the recent credit and housing boom. 
The complex and novel nature of economic fundamentals surrounding bubbles in combination with the new structures to exploit them favors the supremacy of analytical skills in the financial sector. To profit from these opportunities, financial institutions need to hire highly educated and skilled bankers and traders, capable of creating new models and systems, structuring bespoke vehicles and securities, and marketing them to clients. Moreover, the profit opportunities in financial intermediation in times of financial booms attract skilled individuals from other sectors such as research and engineering. Traditional banking services such as lending, brokerage, and underwriting of bonds and stocks of traditional companies, on the other hand, can be much more standardized, require less skills, and generate lower fees.

Consider the recent housing and securitization boom. A myriad of structures has been created to invest in credit and mortgages, such as collateralized debt obligations (CDOs), asset-backed commercial paper conduits (ABCPs), and structured investment vehicles (SIVs). The underlying credits were pooled and structured, and the tranches of these pools recycled in yet further structures. Revenues of financial institutions soared, but they had to employ hoards of mathematicians, IT engineers and quantitative finance specialists to handle these highly complex transactions. The bubbles also created vast profit opportunities for principal trading units and hedge funds by taking proprietary exposures, lurring many graduates from top universities as well as talent from other sectors into financial services. As the Economist put it well, "finance beguiled the bright and ambitious and put them to work in the trading rooms of Wall Street and the City of London." ${ }^{3}$

The resulting impact of asset bubbles and financial deregulation on the wage structure can be best demonstrated with a simple supply and demand framework borrowed from the literature on educational wage differentials (e.g. Katz and Autor, 1999). Consider a real production sector with a Cobb-Douglas production function,

$$
Y_{t}=A_{t} U_{t}^{\gamma} H_{t}^{1-\gamma}
$$

using less-skilled labor (high school equivalent), $U_{t}$, and more-skilled labor (college equivalent), $H_{t}$. $A_{t}$ is a general productivity parameter, while $\gamma$ and $1-\gamma$ represent skill-specific productivity parameters. Let us introduce a financial sector that absorbs rents through the intermediation of bubbles $\left(B_{t}\right)$ according to $R_{t}=\psi B_{t}$ using skilled labor. ${ }^{4}$ It will be shown in the next section that the skill premium in this economy amounts to

$$
\log \frac{w_{t}^{h}}{w_{t}^{u}}=\log \frac{1-\gamma+\psi B_{t} / Y_{t}}{\gamma}-\log \frac{H_{t}}{U_{t}}
$$

\footnotetext{
${ }^{3}$ Economist, January 24th 2009.

${ }^{4}$ I abstract from capital and traditional intermediation for the moment. The next section will explain the financial sector in more details.
} 
Similar to skill-biased technical change in the basic framework (lowering $\gamma$ ), bubbles drive up the skill premium in the economy. Bubbles increase opportunities for skilled workers in financial intermediation which reduces skilled labor in real production, raising the marginal product and compensation of skills in the economy. The rise in wage inequality due to bubbles depends on the amount of rents that can be apprehended, $\psi$, which is determined by factors such as financial regulation and the relative advantage of a country in intermediation.

The next section introduces a model that generates a similar reduced form which allows us to study the impact of bubbles and financial intermediation, the role of financial regulation and globalization, as well as further topics, in more detail.

\section{Model}

\subsection{Description of the model}

Let me briefly outline the key ingredients of the model, before proceeding to a fuller description:

OLG and bubbles: The structure follows the basic overlapping generations (OLG) models with neoclassical production and capital accumulation. The OLG is the simplest intertemporal general equilibrium framework that generates conditions under which rational asset bubbles may arise (see Tirole, 1985; Santos and Woodford, 1997). ${ }^{5}$

Skilled and unskilled workers: Individuals are endowed with heterogeneous skills. There are two groups of individuals, which are labelled "skilled" and "unskilled". Skilled individuals should be interpreted as possessing superior analytical capabilities and/or having enjoyed higher education (e.g. college degree or higher). Unskilled individuals have no such special analytical abilities, and are less educated.

Financial intermediation: Channeling savings into investments requires intermediation services of a financial sector. Financial institutions may engage in traditional intermediation channeling savings into businesses, financing capital needs, and they may engage in intermediation of bubbles, channeling savings into asset bubbles. As motivated in Section 2, the technology of financial intermediation of bubbles is assumed to be more skill-intensive than traditional intermediation (and real production), since handling the complex and novel nature of fundamentals surrounding bubbles requires a high analytical skill set. Whereas traditional intermediation is essential to capital accumulation, intermediation of bubbles is not in our framework. The latter is modelled as a pure rent-seeking activity, where skilled individuals

\footnotetext{
${ }^{5} \mathrm{I}$ am convinced that most bubbles contain significant elements of irrationality. But since this paper is mostly concerned with the impact of bubbles on labor markets - rather than the causes of bubbles - I chose the simpler route of a rational framework.
} 
can join the financial sector to apprehend rents created by asset bubbles. ${ }^{6}$

\subsubsection{Endowments, preferences, and technology}

The economy is populated by a continuum of individuals who live for two periods, and only work when they are young. There are $L$ individuals in each generation (no population growth). Each young individual is endowed either with one unit of skilled labor or with one unit of unskilled labor. There are $u L$ unskilled and $h L=(1-u) L$ skilled workers, with $u \in(0,1)$.

Individuals have logarithmic utility functions in consumption,

$$
U^{i}\left(c_{1, t}^{i}, c_{2, t+1}^{i}\right)=\ln \left(c_{1, t}^{i}\right)+\beta \ln \left(c_{2, t+1}^{i}\right),
$$

and supply their labor inelastically. Young individuals work and use their wage income to consume and save for retirement subject to the budget constraint,

$$
c_{1, t}^{i}+s_{t}^{i} \leq w_{t}^{i} \quad \text { and } \quad c_{2, t+1}^{i} \leq s_{t}^{i}\left(1+r_{t+1}\right)
$$

The consumption good is produced by a competitive real sector, using capital and labor, with the following (Cobb-Douglas) production function:

$$
Y_{t}=\left[\int_{j=0}^{N_{t}} K_{t}(j)^{1 / \theta} d j\right]^{\alpha \theta}\left(A_{t} U_{t}^{Y}\right)^{\gamma}\left(A_{t} H_{t}^{Y}\right)^{1-\alpha-\gamma},
$$

$U_{t}^{Y}$ and $H_{t}^{Y}$ denote total employment of unskilled and skilled workers in the real sector, respectively, and $A_{t}$ the level of labor-augmenting, skill-neutral technology. There is a continuum of differentiated capital goods $K_{t}(j)$ of mass $N_{t}$ available to the real sector. $\theta(>1)$ parametrizes the importance of using a variety of machines, whereas $\alpha$ parametrizes the overall importance of capital in production. $A_{t}$ grows exogenously at rate $g$,

$$
A_{t}=A_{0}(1+g)^{t}
$$

The final good can be turned reversibly into capital goods with the technology $k_{t+1}(j)=$ $k_{t}(j)+s_{t}(j)$.

Firms in the real sector rent capital and labor at market prices, maximizing profits. However, firms cannot finance themselves directly. They need to finance/lease capital goods through financial intermediaries.

\footnotetext{
${ }^{6}$ Murphy, Shleifer and Vishny (1991) make the example of trading in financial markets. Trading might raise market efficiency, but the main gains come from the "transfer of wealth to the smart traders from the less astute". Another example is the creation of financial vehicles and structures for less sophisticated investors to invest in the latest speculative assets such as tech or subprime.
} 


\subsubsection{Traditional financial intermediation}

Financial intermediaries collect savings from individuals, and lend these savings to the real production sector, financing capital goods. The financial sector consists of a continuum of monopolistically competitive intermediaries with measure $N_{t}$, each specialized in a different type of capital good $j$. One should think of financial intermediaries being specialized in different sectors, acquiring differentiated expertise and relationships specific to their sectors covered. Individuals cannot lend directly to the real sector (or search and monitoring is prohibitively expensive), and thus turn to the financial sector to deposit and invest their savings.

Financial intermediaries need to employ a fixed amount of $\phi^{-1}$ units of unskilled labor in each period to be able to operate, that is to build the required expertise, relationships and infrastructure. ${ }^{7}$ Intermediaries set lease rates, $r_{t}^{F}(j)$, and finance themselves at the prevailing market rate on savings, $r_{t}$, on deposits from individuals in order to maximize profits,

$$
\pi_{t}(j)=K_{t}(j)\left[r_{t}^{F}(j)-r_{t}\right]-\phi^{-1} w_{t}^{u}
$$

$w_{t}^{u}$ is the wage rate of unskilled labor. Demand for financing of capital good $j$ is driven by the first-order conditions in the real sector with respect to capital good $j$,

$$
K_{t}(j)=\left(r_{t}^{F}(j)\left[\int_{j=0}^{N_{t}} K_{t}(j)^{1 / \theta} d j\right] /\left(\alpha Y_{t}\right)\right)^{\theta /(1-\theta)} .
$$

Note that the final good is chosen as numéraire. Financial intermediaries optimally set lease rates according to the first-order condition

$$
r_{t}^{F}(j)=\theta r_{t}
$$

$\theta$ determines the pricing power of financial intermediaries. The higher $\theta$, the higher is the spread intermediaries can charge on top of interest rates accruing to depositors. $\theta$ can be thought of as a general measure of market power in the traditional financial sector, while $\phi$ measures productivity. The higher $\phi$, the lower are entry barriers into financial intermediation. Profit flow for financial intermediary $j$ in period $t$ thus amounts to

$$
\pi_{t}(j)=K_{t}(j)[\theta-1] r_{t}-\phi^{-1} w_{t}^{u}=0
$$

which must be zero in equilibrium given free entry into financial intermediation and the assumption that the range of capital goods is sufficiently large such that each intermediary can specialize in a different sector.

\footnotetext{
${ }^{7}$ The use of unskilled labor reflects the fact that traditional intermediation can be more standardized than intermediation of bubbles. This simplifying assumption is rather innocuous, and the main results continue to hold if traditional intermediation needs both skilled and unskilled labor.
} 
In each period, intermediaries must decide whether to operate (and incur the fixed costs of employing $\phi^{-1}$ units of unskilled labor) and, if they operate, must select a sector. Since fixed costs must be incurred in every period, intermediaries' entry decisions affect only the current period. Note the analogy of financial intermediaries to capital good monopolists with fixed costs, which generates a simple yet intuitive structure to model the traditional financial sector. Banks face high fixed costs to build infrastructure, expertise and relationships, which are to a large extend specific to sectors. Once these investments are made, marginal costs of increasing lending volumes are comparatively small. As a result, banks specialize in certain sectors and products in line with empirical observations. ${ }^{8}$

Finally note that the presence of a traditional financial sector and whether it is competitive or not is not crucial for our key results that asset bubbles and financial deregulation increase wage inequality in the economy. Nevertheless, it allows a more comprehensive view of the financial sector and financial regulation.

\subsubsection{Bubbles and financial intermediation}

Asset prices might deviate from market fundamentals in an OLG economy (see Tirole, 1985). Even in a rational, perfect foresight equilibrium, deviations from fundamentals can persist under certain economic conditions. I denote the sum of this aggregate deviations by $B_{t}$, the aggregate bubble. As motivated in Section 2, the complex and novel nature of fundamentals surrounding bubbles creates ample room for uncertainties and discrepancies in valuations. Hence, suppose that capital good sectors in our economy that are more complex, are more susceptible to bubbles than traditional sectors. (Although technological progress is exogenous in our economy, one can imagine that in an economy with an expanding variety of capital goods, the newer sectors are less understood and thus tend to be the sectors with larger valuation discrepancies, e.g. the internet sector.) The aggregate bubble in the economy consists of the valuation discrepancies across sectors,

$$
B_{t}=\int_{j=0}^{N_{t}} B_{t}(j) d j
$$

One can think of these bubbles as paper assets attached to a given capital good sector $j$, which are intrinsically worthless, but valued positively due to sustainable expectations of future growth in value. ${ }^{9}$

\footnotetext{
${ }^{8}$ In the presence of risk, banks optimally operate in several sectors (potentially overlapping with other banks), trading off additional diversification benefits with additional fixed costs of operating in further sectors.

${ }^{9}$ Note that strictly speaking the model is silent about the composition of individual bubbles across sectors, as the composition initially is exogenous, and subsequently indeterminate. There can be random transfers of a bubble from one asset to another over time ("bubble substitution") since individuals can perfectly insure by holding the representative portfolio (see Tirole, 1985).
} 
The complex nature of bubbles favors the supremacy of skilled individuals in exploiting opportunities around such distortions. Skilled workers can collect rents from bubbles according to the following technology:

$$
R_{t}^{i}=\frac{\psi B_{t}}{H_{t}^{F}}
$$

where $\psi$ is an exogenous fraction of the bubble that can be absorbed by skilled workers each period, and $H_{t}^{F}$ denotes total skilled labor engaged in financial intermediation of bubbles. The larger the bubbles, the more rent opportunities are available to skilled individuals. The more skilled individuals are already engaged in bubble intermediation, however, the less each individual earns. A skilled worker can collect a share of the total rent proportional to its relative effort, $1 / H_{t}^{F}$. Intermediation of bubbles is attractive if rent opportunities exceed opportunity costs of $w_{t}^{h}$ from being employed in the real sector. Bubbles are always intermediated in the case of $\psi>0$, since a skilled worker could apprehend the entire rent with an arbitrarily small effort if bubbles were not yet intermediated.

The simple rent-seeking technology with an exogenous fraction $\psi$ of bubbles that can be absorbed reflects the observed fee structure in the financial sector. Transaction and management fees of banks and hedge funds are often fixed percentages on loan and asset volumes, especially in the more innovative, less competitive segments. Hence banks benefit from inflating asset valuations in the economy. Finally, aggregate bubbles are exogenous and deterministic in the basic framework. Appendix B outlines an extension with stochastic bubbles that may burst and a technology with which skilled individuals are able to create new bubbles.

\subsubsection{Savings, investments, and labor markets}

Logarithmic utility in the OLG model gives rise to the familiar aggregate savings function,

$$
S_{t}=\frac{\beta}{1+\beta}\left[u w_{t}^{u}+(1-u) w_{t}^{h}\right] L .
$$

These savings are deposited at financial intermediaries, which channel them into investments,

$$
I_{t}=\int_{j=0}^{N_{t}} K_{t+1}(j) d j+B_{t}
$$

that is capital for the real sector and bubbles. Individuals are willing to invest in both types of investments if they yield the same return net of intermediation fees,

$$
(1-\psi) B_{t+1} / B_{t}=1+r_{t+1}
$$

Since bubbles do not pay any dividends, the aggregate bubble must grow at the rate of interest net of intermediation fees, $\psi$.

Finally, aggregate supply of unskilled and skilled labor is equal to $u L$ and $h L=(1-$ $u) L$, respectively, as individuals inelastically supply one unit of labor. Aggregate demand for 
unskilled labor is the sum of market demands to produce consumption goods $\left(U_{t}^{Y}\right)$ and provide financial intermediation for capital goods $\left(U_{t}^{F}\right)$. Aggregate demand for skilled labor is the sum of market demands to produce consumption goods $\left(H_{t}^{Y}\right)$ and to capture rents by providing intermediation for bubbles $\left(H_{t}^{F}\right)$. Labor market clearing requires

$$
\begin{aligned}
u L & =U_{t}^{Y}+U_{t}^{F}=U_{t}^{Y}+\phi^{-1} N_{t}, \\
(1-u) L & =H_{t}^{Y}+H_{t}^{F} .
\end{aligned}
$$

Wages are determined by marginal products in real production,

$$
\begin{aligned}
w_{t}^{u} & =\left(U_{t}^{Y}\right)^{-1} \gamma Y_{t}=\left(u L-\phi^{-1} N_{t}\right)^{-1} \gamma Y_{t}, \\
w_{t}^{h} & =\left(H_{t}^{Y}\right)^{-1}(1-\alpha-\gamma) Y_{t} .
\end{aligned}
$$

\subsection{Solution of the model}

We are now ready to study the decentralized equilibrium of the economy described in the previous section, summarized by the following definition:

Definition 1 An equilibrium in our economy is a sequence of prices and allocations such that

(a) individuals maximize utility given asset holdings of the initial old generation at time $t=0$ of $\left[K_{0}(j)\right]_{j=0}^{N_{t}}$ and $B_{0}$, and taking the time path of $r_{t}, B_{t}, w_{t}^{u}$ and $w_{t}^{h}$ as given,

(b) real sector maximizes profits taking the time path of $\left[r_{t}^{F}(j)\right]_{j=0}^{N_{t}}, w_{t}^{u}$ and $w_{t}^{h}$ as given,

(c) financial intermediaries choose $r_{t}^{F}(j)$ and $K_{t}(j)$ to maximize profits taking the time path of $r_{t}$ and $w_{t}^{u}$ as given,

(d) the evolution of the range of financial intermediaries, $N_{t}$, is determined by free entry,

(e) skilled individuals decide whether to engage in intermediation of bubbles to maximize labor income taking the time path of $w_{t}^{h}$ as given,

(f) the aggregate bubble evolves arbitrage-freely according to equation (8), and

(g) factor prices, $r_{t}, w_{t}^{u}$ and $w_{t}^{h}$, are such that all markets clear.

Let us start with characterizing the equilibrium without bubbles, $B_{t}=0$, before proceeding to the equilibrium with bubbles, $B_{t}>0$.

\subsubsection{Equilibrium without bubbles}

The range of intermediated capital goods, $N_{t}$, is determined by free entry. Due to symmetry, all financial intermediaries set the same rental rates, $r_{t}^{F}(j)=r_{t}^{F}$, and the real sector thus rents the same quantity of each capital good, $K_{t}(j)=K_{t}$. The free entry condition for financial intermediation (equation 4) becomes

$$
\phi[\theta-1] r_{t} K_{t}=w_{t}^{u} .
$$


We can combine this condition with the lease rate setting rule, the demand for capital goods, and wages (equations 2, 3 and 10) to obtain

$$
N_{t}=\frac{\phi(\theta-1) \alpha u L}{\theta \gamma+(\theta-1) \alpha} \equiv N
$$

which is constant over time. As the share accruing to capital grows at the same rate as wages (given Cobb-Douglas technology), the revenue base and fixed operating costs of financial intermediaries grow at the same rate for a given $N$. Thus $N$ does not need to adjust to keep the free entry condition fullfilled. $N$ is increasing in the price setting power $(\theta)$ and productivity $(\phi)$ of traditional intermediation.

Next, real production technology can be simplified to

$$
Y_{t}=\left(N^{\theta} K_{t}\right)^{\alpha}\left(A_{t} U_{t}^{Y}\right)^{\gamma}\left(A_{t} H_{t}^{Y}\right)^{1-\alpha-\gamma}=A_{t} L\left(N^{\theta} k_{t}\right)^{\alpha}\left(u_{t}^{Y}\right)^{\gamma}\left(h_{t}^{Y}\right)^{1-\alpha-\gamma}
$$

where $k_{t} \equiv A_{t}^{-1} L^{-1} K_{t}, u_{t}^{Y} \equiv L^{-1} U_{t}^{Y}$ and $h_{t}^{Y} \equiv L^{-1} H_{t}^{Y}$. Setting savings equal to investments (equations 6 and 7 , setting $B_{t}=0$ for all $j$ ) yields the fundamental law of motion of our OLG economy with a financial sector but without bubbles:

$$
N(1+g) k_{t+1}=\frac{\beta}{1+\beta}\left[\frac{u \gamma}{u-(\phi L)^{-1} N}+(1-\alpha-\gamma)\right] y_{t}
$$

with

$$
y_{t}=\left(N^{\theta} k_{t}\right)^{\alpha}\left(u-(\phi L)^{-1} N\right)^{\gamma}(1-u)^{1-\alpha-\gamma} .
$$

Note that without a financial sector (by setting $N=1, \theta=1$, and $\phi=\infty$ ) our economy collapses to the familiar canonical OLG equilibrium with Cobb-Douglas technology and logarithmic preferences. For a given $N$, the financial sector reduces real production as resources are needed in intermediation. On the other hand, it increases the labor share in income, as part of the capital income flows into wages to compensate intermediation services of the young.

The steady state with $k_{t+1}=k_{t}=\bar{k}$ is determined by:

$$
\bar{k}=\left(\frac{\beta\left[u \gamma /\left(u-(\phi L)^{-1} N\right)+(1-\alpha-\gamma)\right] N^{\alpha \theta}\left(u-(\phi L)^{-1} N\right)^{\gamma}(1-u)^{1-\alpha-\gamma}}{(1+\beta)(1+g) N}\right)^{1 /(1-\alpha)} .
$$

An increase in the price setting power of the financial sector $(\theta)$ increases the variety of capital goods intermediated $(N)$, which raises real output and the savings rate for a given level of capital. ${ }^{10}$ However, it may lower capital in the long run, $\bar{k}$. Computations have revealed both cases where $\bar{k}$ either decreases or increases as a result, depending on parameter values. Even if $\bar{k}$ decreases, computations have never produced a case where long run output, $\bar{y}$, suffers from a rise in $\theta$. Raising productivity of the financial sector $(\phi)$ has similar effects as a rise in $\theta$.

\footnotetext{
${ }^{10}$ Output per efficiency units is increasing in the variety of capital/intermediaries, $\partial y_{t} / \partial N=$ $y_{t}[\alpha \theta / N-\gamma /(u \phi L-N)]>0$, cf. equation (11).
} 
Variety of capital goods and output both increase, whereas the savings rate is lowered, for given $k_{t}$. Computations never revealed cases where savings for a given $k_{t}$ decrease as a result. To sum up, strengthening the traditional financial sector (by increasing $\theta$ and/or $\phi$ ) is beneficial for real output and wages, through the positive effect of raising the variety of intermediated capital goods. The effect on aggregate capital income accruing to the old, $\alpha \bar{y} / \theta$, on the other hand, depends on whether the positive effect of the output expansion outweighs the negative effect of higher markups. Computations have revealed both cases.

Finally, consider the effect on interest rates accruing to depositors in the steady state,

$$
\bar{r}=\frac{\bar{r}^{F}}{\theta}=\frac{\alpha \bar{y}}{\theta N \bar{k}}
$$

which is equal to the marginal product of capital goods less the markup for intermediation. While the marginal product of capital may rise or fall due to increasing $\theta$, the net interest rate, $\bar{r}$, falls in all computations. Like in the standard OLG model, the marginal product of capital is an important element of the economic conditions under which bubbles may arise. Not surprisingly, financial intermediation plays an important role, too, in shaping these conditions.

\subsubsection{Equilibrium with bubbles}

Individuals are willing to invest in bubbles as well as productive capital if both assets yield the same return net of intermediation costs, see equation (8). Hence, bubbles must grow according to

$$
\frac{B_{t+1}}{B_{t}}=\frac{1+r_{t+1}}{1-\psi}=\frac{1+r_{t+1}^{F} / \theta}{1-\psi}
$$

as bubbles do not pay out any dividends, and financial intermediation rents $(\psi)$ must be covered. However, if bubbles grew faster than the economy in the long run, they could not arise in the first place because bubbles which outgrow the economy are not sustainable. Thus bubbles can only arise if their growth rate is (equal to or) lower than the growth rate of the economy in the long $\operatorname{run}, \lim _{t \rightarrow \infty} B_{t+1} / B_{t} \leq 1+g$. Similar to the canonical OLG model without financial intermediation, bubbles can only arise if marginal productivity of capital $\left(\bar{r}^{F}\right)$ is sufficiently low: ${ }^{11}$

$$
1+\bar{r}^{F} / \theta<(1-\psi)(1+g)
$$

In contrast to the canonical model, however, the marginal product must not be lower than the growth rate if pricing power in traditional intermediation is sufficiently high. On the other hand, a marginal product lower than economic growth does not necessarily generate conditions

\footnotetext{
${ }^{11}$ Starting in the bubbleless steady-state, $\bar{k}$, bubbles crowd out part of the capital, increasing the return on capital, $r_{t+1}>\bar{r}^{F}$. Hence, bubbles can only arise if the marginal product of capital in the bubbleless steady-state is sufficiently low.
} 
for bubbles if rents in intermediation of bubbles are sufficiently high. Since $\theta$ lowers net interest rates, bubbles are more likely to arise if market power in traditional intermediation is high. On the other hand, bubbles are less likely to arise if rents in intermediation of bubbles are too high. See Appendix A for more details on welfare, dynamic efficiency, and conditions for bubbles.

In an equilibrium with bubbles, it is always attractive for skilled individuals to apprehend rents (see equation 5), hence wages in the real sector must reflect this opportunity,

$$
w_{t}^{h}=\left(H_{t}^{F}\right)^{-1} \psi B_{t} .
$$

Jointly with marginal productivity in the real sector and labor market clearing (equations 9 and 10), this condition determines relative employment of skilled in the real and financial sector, respectively:

$$
h_{t}^{Y}=\frac{(1-u)(1-\alpha-\gamma) y_{t}}{\psi b_{t}+(1-\alpha-\gamma) y_{t}} \text { and } h_{t}^{F}=1-u-h_{t}^{Y},
$$

where $b_{t} \equiv A_{t}^{-1} L^{-1} B_{t}$. The capital accumulation equation in the presence of bubbles thus becomes:

$$
N(1+g) k_{t+1}+b_{t}=\frac{\beta}{1+\beta}\left[\frac{u \gamma}{u-(\phi L)^{-1} N}+\frac{\psi b_{t}}{y_{t}}+(1-\alpha-\gamma)\right] y_{t}
$$

with

$$
y_{t}=\left(N^{\theta} k_{t}\right)^{\alpha}\left(u-\frac{N}{\phi L}\right)^{\gamma}\left(\frac{(1-u)(1-\alpha-\gamma) y_{t}}{\psi b_{t}+(1-\alpha-\gamma) y_{t}}\right)^{1-\alpha-\gamma} .
$$

The accumulation equation is similar to the one above, except that now the aggregate bubble absorbs part of the savings, lowers real output as resources are redeployed in intermediation of bubbles, and drives up wages of skilled workers, increasing the savings rate.

The accumulation equation jointly with the no-arbitrage condition, equation (8),

$$
(1-\psi)(1+g) b_{t+1}=\left(1+\frac{\alpha y_{t+1}}{\theta N k_{t+1}}\right) b_{t},
$$

describe the dynamic system of the economy with bubbles. The equilibrium can best be illustrated with a phase diagram borrowed from Tirole (1985) and Weil (1987), see Figure 2. There is an "asymptotically bubbly equilibrium" where the bubble grows at the same rate as the economy in the long run, and thus the bubble per efficiency units converges to $\hat{b}$ and capital to $\hat{k}$. If the bubble starts below this asymptotically bubbly path, the economy eventually converges to the "asymptotically bubbleless" steady state, which corresponds to the steady state from above, with $\bar{k}$ and $\bar{b}=0$. Since in that case the capital stock remains relatively high with bubbles absorbing relatively little savings, interest rates remain comparatively low, and thus the bubble grows relatively slowly, and ultimately becomes marginal compared to the economy. Bubbles cannot start above the asymptotically bubbly path, as they would end up outgrowing the economy, leading to negative capital. 


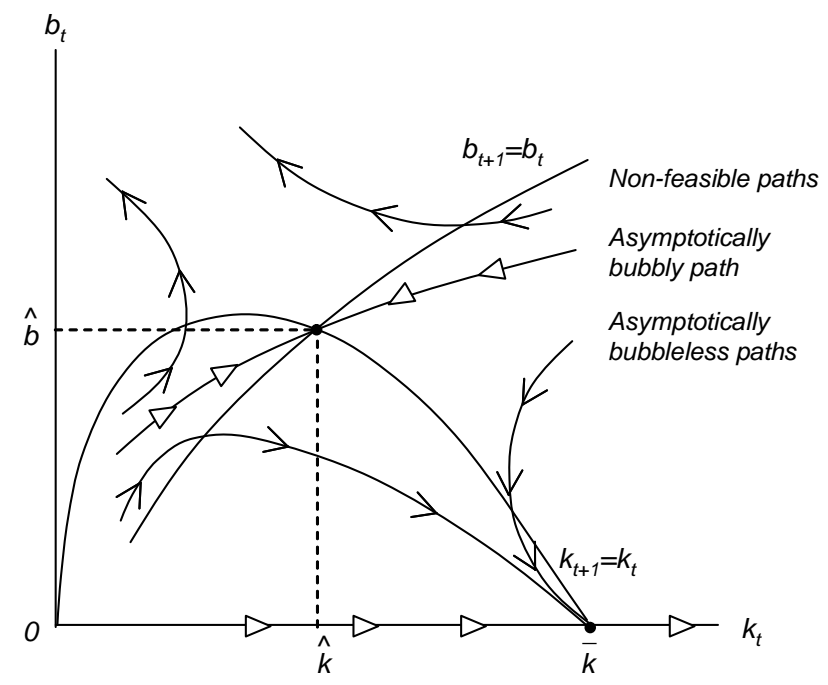

Figure 2: BubblyEquilibrium

Computations have revealed that increasing pricing power $(\theta)$ or productivity $(\phi)$ in the traditional financial sector shifts both the $b_{t+1}=b_{t^{-}}$and $k_{t+1}=k_{t^{-}}$locus up, creating more "room" for bubbles. Whereas increasing rents in intermediation of bubbles $(\psi)$ shifts the loci down, restricting the size of bubbles. Nevertheless, aggregate rents $\left(\psi b_{t}\right)$ in the asymptotically bubbly steady state increase in $\psi$.

\subsection{Interpretation of the model}

Let us proceed to the content of the model. The impact of asset bubbles on labor markets in our economy can be summarized by the following proposition:

Proposition 1 Given the described economy, asset bubbles $\left(b_{t}\right)$ increase opportunities for skilled workers in the financial sector $\left(h_{t}^{F}\right)$, leading to a rise in wage inequality in the economy as relative wages of skilled workers $\left(w_{t}^{h} / w_{t}^{u}\right)$ are pushed up.

The relative wages of skilled workers can be readily calculated (using equations 10 and 14),

$$
\frac{w_{t}^{h}}{w_{t}^{u}}=\frac{\left(u-(\phi L)^{-1} N\right)\left(\psi b_{t} / y_{t}+(1-\alpha-\gamma)\right)}{\gamma(1-u)}
$$

Demand for skilled workers in financial services is given by

$$
h_{t}^{F}=1-u-\frac{(1-u)(1-\alpha-\gamma) y_{t}}{\psi b_{t}+(1-\alpha-\gamma) y_{t}} .
$$

It is straightforward to verify the proposition. 
Note that taking logs of the relative wages generates a very similar reduced form as the one shown in Section 2:

$$
\log \frac{w_{t}^{h}}{w_{t}^{u}}=\log \frac{\theta \gamma}{\theta \gamma+[\theta-1] \alpha}+\log \frac{(1-\alpha-\gamma)+\psi b_{t} / y_{t}}{\gamma}-\log \frac{1-u}{u},
$$

using equations (11) and (15). The more skilled workers the financial sector absorbs relative to unskilled workers, the lower is the relative ratio of skilled workers in the real sector $\left(h_{t}^{Y} / u_{t}^{Y}\right)$, and thus the higher their relative marginal products and wages. Bubbles create rent opportunities in the financial sector, attracting skilled individuals, which increases their wages and employment in the financial sector, while wages and employment of unskilled workers remain less affected.

\subsubsection{The role of financial regulation}

Financial regulation subjects financial institutions to certain requirements and restrictions, shaping the opportunity set in which the financial sector operates. Financial regulation thus has important implications for our results.

Let us view financial regulation policy in our framework as a triplet $\left(\theta^{G}, \phi^{G}, \psi^{G}\right)$. One can think of a (governmental) organization that can affect the parameters of financial intermediation, and thus set $(\theta, \phi, \psi)=\left(\theta^{G}, \phi^{G}, \psi^{G}\right)$ within certain boundaries. For example, the organization could stimulate competition in the financial sector, lowering the market power of traditional intermediation, $\theta$. It could increase reporting and risk management requirements, lowering productivity in traditional intermediation, $\phi$. Or it could impose restrictions on leverage and financial structures, lowering rent opportunities around bubbles, $\psi$. The effect of stricter financial regulation directly follows from our discussion of the solution and proposition above:

Corollary 1 Traditional intermediation: Tightening financial regulation by decreasing $\theta^{G}$ and $\phi^{G}$ lowers the likelihood of conditions and maximum size of bubbles.

Intermediation of bubbles: Tightening financial regulation by decreasing $\psi^{G}$ reduces wage inequality in the presence of bubbles.

Traditional intermediation is important for the proliferation of a broad variety of innovations. Weakening traditional intermediation decreases the range of intermediated capital goods that are available to the real sector, lowering real output. As a consequence, net interest rates increase and savings decrease, lowering the likelihood of conditions and maximum size of bubbles, however at the cost of lower real production. Loosely speaking, the "price" of innovation, partially enabled by financial intermediation, is increased complexity in fundamentals, favoring the emergence of bubbles. Restricting traditional intermediation lowers innovation and capital 
in the economy, and thus complexity and the likelihood of bubbles. The disadvantages of too strict a regulation, that is of less innovation and capital, however, clearly outweigh the benefits of less bubbles.

Restrictive regulation of intermediation of bubbles reduces wage inequality in a bubbly economy. Since rent seeking absorbs skilled workers, redistributing income and reducing real output without creating any social benefit, restrictive regulation of these activities is certainly more appropriate. In the real world the distinction between fundamental intermediation and rent seeking activities unfortunately is often not that easy. Regulators thus face the difficult task to find the delicate balance between curbing excesses while not choking off an important engine of the economy.

\subsubsection{Globalization of financial markets and services}

Consider a simple two-country extension of our model, with the two countries home and abroad (marked with an asterisk). Let us assume perfect capital (and bubble) mobility, no trading costs for consumption goods and financial intermediation services, and immobile labor markets. The two countries are identical, except that the financial sector abroad has an advantage in capturing rents of bubbles:

$$
R_{t}=\frac{a}{a H_{t}^{F}+a^{*} H_{t}^{F *}} \psi\left(B_{t}+B_{t}^{*}\right) \quad \text { and } \quad R_{t}^{*}=\frac{a^{*}}{a H_{t}^{F}+a^{*} H_{t}^{F *}} \psi\left(B_{t}+B_{t}^{*}\right),
$$

with $a^{*}>a$. The advantage in intermediation of bubbles translates into higher wage inequality abroad:

Corollary 2 Given the described two-country set-up, the country with an advantage in capturing rents from intermediation of bubbles experiences a steeper rise in wage inequality and financial sector employment of skilled workers if bubbles arise in any of the two countries.

The difference in wages of skilled workers between abroad and home is driven by the advantage of abroad in capturing rents of bubbles:

$$
w_{t}^{h *}=\frac{a^{*}}{a H_{t}^{F}+a^{*} H_{t}^{F *}} \psi\left(B_{t}+B_{t}^{*}\right)>w_{t}^{h} \geq \frac{a}{a H_{t}^{F}+a^{*} H_{t}^{F *}} \psi\left(B_{t}+B_{t}^{*}\right) .
$$

If $a$ is sufficiently low compared to $a^{*}$, employment of skilled workers in intermediation at home is zero, $H_{t}^{F}=0$. Since wages of skilled workers are higher abroad, employment of skilled workers in intermediation is higher and in real production lower than at home. Thus wages of unskilled workers abroad tend to be lower as well. However, lower wages create an advantage for traditional intermediation abroad, partially or fully keeping up wages for unskilled at the levels of home. ${ }^{12}$ Hence, the country with the advantage in intermediation of bubbles, experiences

\footnotetext{
${ }^{12}$ Wages of unskilled workers abroad are equal or smaller than wages at home, $w_{t}^{u *}=$ $\left(K_{t}(j)+K_{t}^{*}(j)\right)[\theta-1] r_{t} / \phi \leq w_{t}^{u}$, with $=$ if $U_{t}^{K}>0$.
} 
higher wage inequality and a larger financial sector if bubbles arise. Consequently, the other country has a larger real sector (with more labor and capital).

The advantage of a country in intermediation of bubbles may be driven by its (less strict) financial regulation policy, or by increasing returns to scale (IRS) due to local spillovers in intermediation of bubbles:

$$
a=a\left(H_{t}^{F}\right) \quad \text { and } \quad a^{*}=a\left(H_{t}^{F *}\right), \quad \text { with } \quad a^{\prime}(\cdot)>0
$$

Traders and bankers clearly benefit from the proximity to each other because of (in-)formal networks, multitude of outside opportunities, vicinity to market action and sentiment, and other factors. For example, the majority of large European investment banks have centralized their more complex trading, structuring, advisory, and originating activities in London.

In the case of IRS, multiple equilibria arise, and thus history and expectations help determining final outcomes. The country with a head start in intermediation (or the country expected to become a financial center) ends up being the predominant financial center of a region. The set of financial regulation policy in the critical stage of financial development is decisive in this case. For London and New York most certainly both regulation and increasing returns play an important role in their dominance as financial centers which will be discussed in the empirical section in more detail.

\subsubsection{On the finance/nonfinance wage gap}

Finally, the empirical evidence presented in the introduction (also see next section) indicates that individuals with similar levels of education, experience, and other relevant characteristics seem to earn a significant premium by working in the financial sector as opposed to nonfinancial sectors in the last decades, and that this premium has increased in the past years. How can we account for such a wage gap in our framework?

With the total rent being shared among financiers participating in intermediation of bubbles, insiders already engaged in intermediation have an incentive to protect their rents from new entrants. Alternatively, certain financiers have better access to such rents through (family) relationships, networks, and other dispositions. As a consequence, the ability to capture rents varies across skilled individuals,

$$
R_{t}^{i}=\frac{\xi(i)}{\int_{k=I}^{L} \xi(k) d k} \psi B_{t} \quad \text { with } \quad \xi(i) \geq \xi(j) \text { for } i>j, \quad \text { and } \quad \frac{\xi(I)}{\int_{k=I}^{L} \xi(k) d k} \psi B_{t}=w_{t}^{h} .
$$

$I$ determines a cutoff below which skilled individuals do not participate in rent seeking. The higher $\xi(i)$, the higher is the share of the rent a person $i \geq I$ is allocated due to better access. Hence during a financial boom the wage gap between the average skilled individual working in finance and a skilled individual working in non-finance widens. 
One could think of further labor market frictions and (potentially unobserved) heterogeneities that would lead to rising finance/non-finance wage gaps in times of booming financial markets.

\subsubsection{Summary of results and empirical implications}

In preparation for the empirical investigation, let us briefly summarize the main results of our theoretical framework: First, the global opportunity set for skilled individuals in financial intermediation is driven by the interaction of asset bubbles and financial regulation. The emergence of asset bubbles increases wage inequality and financial sector employment of skilled labor, and the rise is reinforced by financial deregulation (i.e. looser regulation).

Second, in an environment of asset bubbles and loose financial regulation, countries with a comparative advantage in financial intermediation experience a steeper rise in inequality and financial sector employment of skills. The comparative advantage may result from looser financial regulation relative to other countries, increasing returns due to local spillovers in intermediation, and other factors favorable to financial institutions.

Third, wages in finance may decouple from wages in other sectors. If insiders are able to protect rents in financial intermediation from outsiders, if tastes in careers differ across individuals, or if other frictions slow down adjustments across sectors, bubbles and deregulation may create and inflate a wage gap between finance and non-finance.

Lastly, our framework has been silent about the causes of bubbles. A natural extension would introduce the possibility for skilled individuals to create bubbles. ${ }^{13}$ In an economy characterized by high savings and low interest rates, there is a high demand for new investment opportunities. Smart individuals might exploit this demand by creating bubbles, such as the latest internet start-up or CDO squared, especially if opportunities and wages in the "real economy" are not sufficiently attractive. In such an environment, one asset bubble might chase the next, keeping wage inequality at elevated levels. Deregulation and low real investment opportunities could trigger such a cycle of bubbles and high inequality. Appendix B outlines such an extension.

\footnotetext{
${ }^{13}$ Strictly speaking, skilled individuals have the capability to persuade other individuals that their intrinsically worthless assets have positive values by spending time and effort in developing a persuasive story around the value of their (paper) assets.
} 


\section{International evidence}

This section evaluates wage and employment data of the four largest advanced OECD countries with comparable household survey data available: the U.S., Germany, U.K., and France. ${ }^{14}$ The aim is to document and compare the development of wage and employment structures over the past decades, providing suggestive evidence for the theoretical framework discussed above.

The U.S. and U.K. spearheaded the global deregulation of financial markets and services starting in the 1970s, which accelerated substantially in the 1980s under Reagan and Thatcher. Germany and France eventually followed but at a slower pace. As a result of these and other factors, the U.S. and U.K. could build large comparative advantages in intermediation translating into higher financial activities than in Germany and France. Motivated by these observations, wage and employment structures in the financial sector are studied next, contrasting the Anglo-Saxon with the Continental European experience over the past decades. Finally, general trends in wage inequality are compared across countries with special attention turned to the timing of deregulation and the rise of asset bubbles.

The wage and employment data comes from a variety of surveys such as the U.S. Current Population Survey (CPS), the U.K. General Household Survey / British Household Panel Survey (GHS/BHPS), the French Labor Force Survey (LFS; enquête emploi), and the German Socio-Economic Panel (SOEP). Trends in wage inequality are studied using simple wage regressions with the usual controls as well as dummies and interactions for the financial sector.

\subsection{A brief history of financial regulation and financial centers}

According to our framework, the demand and rent opportunities for skilled individuals in financial intermediation are determined by the size of (global) bubbles, as well as by the country's financial regulation and comparative advantage in intermediation. The comparative advantage, in turn, is shaped by the stringency of regulation relative to other countries, by history given increasing returns to scale in financial intermediation, and by other factors favorable to financial institutions.

The global deregulation of financial markets and services of the past three decades was led by the U.S. and U.K., initiated in the 1970s with the end of Bretton Woods. ${ }^{15}$ Deregulation gained momentum in the 1980s under Reagan and Thatcher. As a consequence of floating currencies, capital controls were abandoned by the U.S. and U.K. Reagan signed the GarnSt. Germain Depository Institutions Act in 1982, deregulating the Savings and Loan (S\&L)

\footnotetext{
${ }^{14}$ For Japan, only aggregated household survey data is available (Japanese Basic Survey of Wage Structure, BSWS) and thus needs to be analyzed differently.

${ }^{15}$ Economist, Oct 16th 2008. In 1971, Nixon suspended the dollar's convertibility into gold, and in 1979 exchange controls were stopped in the U.K.
} 


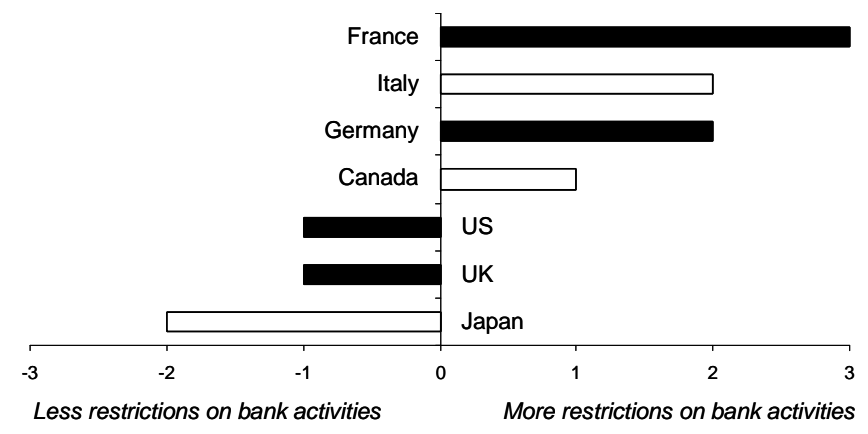

Figure 3: Change in the index of overall restrictions on bank activites from 1998-2007 (Survey; Barth et al. 2008)

industry in the U.S., which contributed to the subsequent S\&L crisis, and sawed some of the seeds for the recent housing boom (e.g. allowed adjustable rate mortgages). Starting in the 1980s, the Glass-Steagall Act which separated commercial and investment banking in the U.S. was gradually dismantled and finally repealed in 1999. The U.K. followed suit with the "Big Bang" deregulation of Thatcher in 1986 (Stock Exchange Agreement and Financial Services Act), which among other changes allowed foreign financial firms into the market, and ignited the rise of proprietary trading. ${ }^{16}$ Continental Europe eventually followed but at a slower pace. For example in the highly fragmented German banking market, state guarantees of the public-sector banks (Sparkassen and Landesbanken) were only abrogated as recently as in 2005 upon pressure of private-sector banks. And a recent study by Barth, Caprio and Levine (2008) indicates that Germany and France have rather increased restrictions on bank activities relative to the U.S. and U.K. over the past ten years, see Figure 3.

History and increasing returns to scale due to local spillovers are other important drivers of the comparative advantages of the U.S. and U.K. in financial intermediation. The origins of New York as financial hub for the American market can be traced to the 18th century when traders started gathering under a buttonwood tree on Wall Street, laying the foundations of the New York Stock exchange. The history of London as financial center goes back to the 17th century with the foundation of the Bank of England, and the Napoleonic Wars during which the financial center of Europe moved from Amsterdam to London (e.g. Buchinsky and Polak, 1993). The head start of Wall Street and the City of London translated into persistent advantages due to a critical amassment of financial activity. As discussed above, traders and bankers benefit from proximity to each other due to (in-)formal networks, multitude of outside opportunities, and vicinity to market action and sentiment. Futhermore, the two cities offer other advantages to financial firms such as a multitude of international air links, telecommunications networks, English as official language, robust financial exchanges, and deep and multinational talent

\footnotetext{
${ }^{16}$ See Economist, Sep 13th 2007 and Oct 16th 2008 for more details
} 


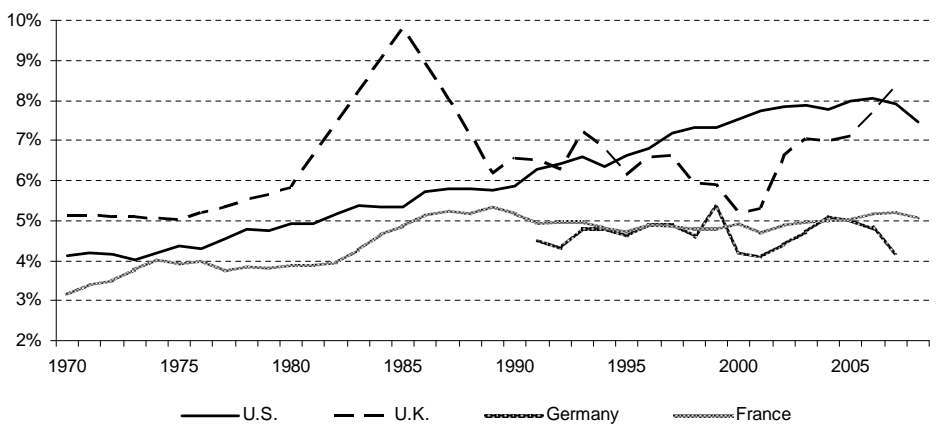

Figure 4: Share of financial intermediation in GDP (Gross Value Added; U.S. Industry Accounts, U.K. National Accounts, INSEE/Comptes Nationaux, Eurostat)

pools. ${ }^{17}$ A recent survey of senior financial services professionals on the competitiveness of financial centers ranked London and New York City clearly ahead of Frankfurt and Paris. ${ }^{18}$

The advantages of the U.S. and U.K. in financial intermediation manifest themselves in the relative levels of financial activity. As shown in Figure 4, the share of financial intermediation in GDP is substantially larger in the Anglo-Saxon economies than in Germany and France, and has widened over the past decades. The share in the U.S. has doubled since the mid 1970s, while the share in the U.K. spurted in the 1980s under Thatcher's Big Bang, retraced thereafter, and started growing again substantially after 2000. The development in France and Germany has been comparatively flat.

Figure 5 shows net exports of financial services in the past decades. Net exports in the U.K. have been consistently positive and increasing over time, as financial institutions have served the European market out of London (Germany and France being the most important importers in Europe). ${ }^{19}$ The trade balance of the U.S. in financial services has been fluctuating around zero as New York has focused on the domestic market, exporting financial services mainly to other U.S. states.

Given these observations, skilled workers should have experienced a larger expansion of their opportunity set in financial intermediation in the U.S. and U.K. than in Germany and France in periods of growing asset bubbles. And the (global) opportunity set should have received a critical boost during the Reagan and Thatcher era. Let us now turn to the labor market data, documenting and contrasting the developments in the U.S. and U.K. with Germany and France.

\footnotetext{
${ }^{17}$ Economist, Sep 13th 2007

18 "The Competitive Position of London as a Global Financial Centre", Corporation of London, 2005. The most important competitive factors are availability of skilled personnel, regulatory environment, and access to international financial markets.

19 "UK Financial Sector Net Exports 2008", IFSL Research (IMF data)
} 


\subsection{Wage and employment structure in the financial sector}

Figure 6 plots the (log of the) relative wage of workers employed in financial intermediation to workers employed in other sectors over time. ${ }^{20}$ In the U.S., the finance/non-finance wage gap started to increase substantially in the 1980s, around the time of the deregulation initiated by Reagan (see also Philippon and Reshef, 2008). The rise was briefly interrupted during the S\&L crisis, and reached a first peak at the height of the dot-com bubble. Retracing somewhat thereafter, the gap widened again during the recent housing and securitization boom. The U.K. shows a similar pattern around the recent peaks in valuation. In contrast to the U.S., the wage gap in France and Germany have been relatively stable over the past two decades.

The left panel of Figure 7 shows the share of higher-educated workers (college equivalent) who were employed by the financial sector. The share has been sharply rising in the U.S., indicating that the financial sector has increased demand for skills in the U.S. economy. In the U.K. the picture is less clear. In France it rather has been receding over the past decades. However, in Germany the share has been rising, too. The corresponding share of lower-educated workers has been trending down both in the U.S., U.K., and France, yet in Germany it has increased somewhat, too.

The development of finance/non-finance wage gaps and employment structures suggest that financial sector employees, especially with higher education, have been strongly benefiting in the era of deregulation and financial booms in the U.S. In U.K. the picture is less clear, however the wage premium in finance has rather increased over the past year. In France, there is no evidence that the financial sector has increased wages in finance and demand for skills, in line with the rather stationary wage inequality over the past decades. In Germany, the evidence

\footnotetext{
${ }^{20}$ The relative wages are estimated with cross-section log weekly earnings regressions on the financial sector dummy, controlling for education, a quartic in experience, regions, sex and race, interactions between sex, race, and experience. Given the differences in data sets across countries, differences in levels should not be overemphasized, and the present analysis focuses on trends.
}

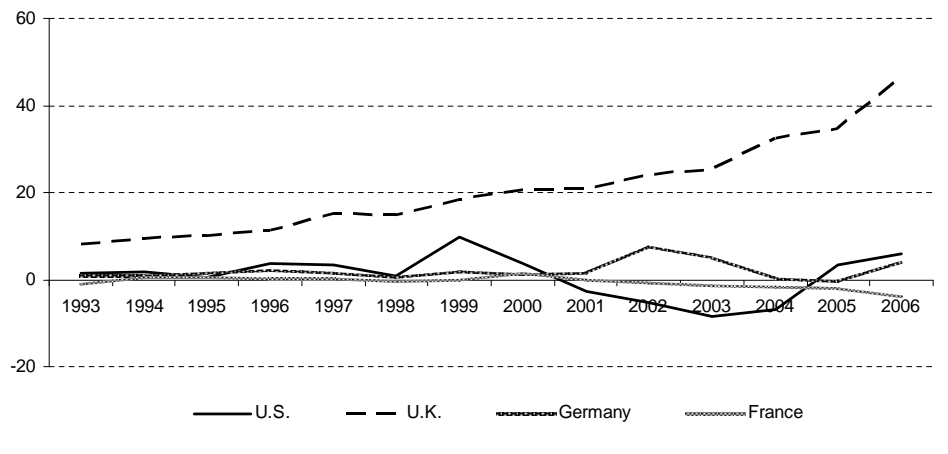

Figure 5: Financial services trade balances ( $\$$ bn; IMF, International Financial Services, London) 


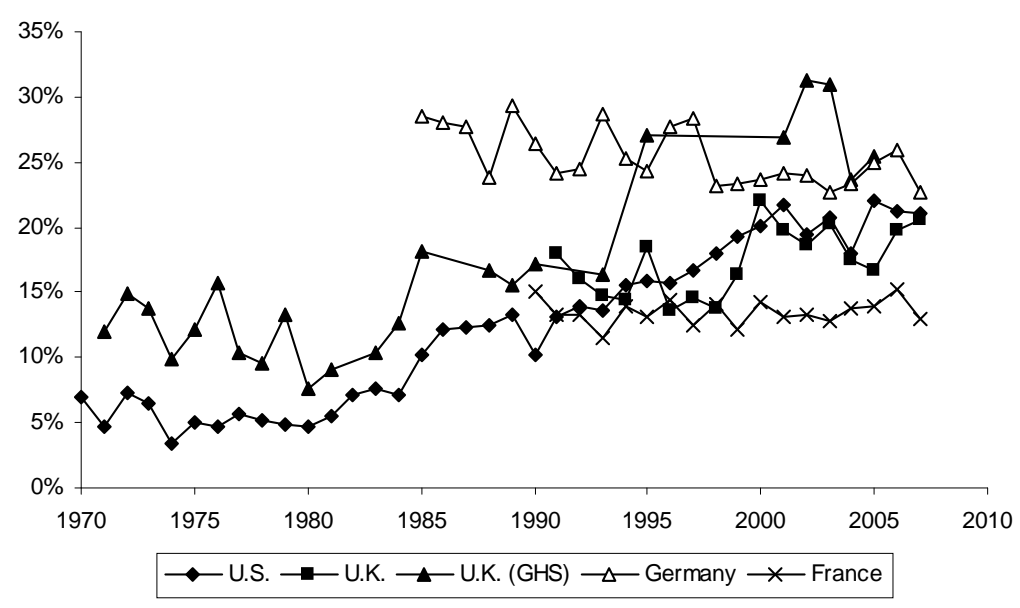

Figure 6: Finance/non-finance wage gaps (Wage regressions CPS, BHPS, GHS, SOEP, LFS)
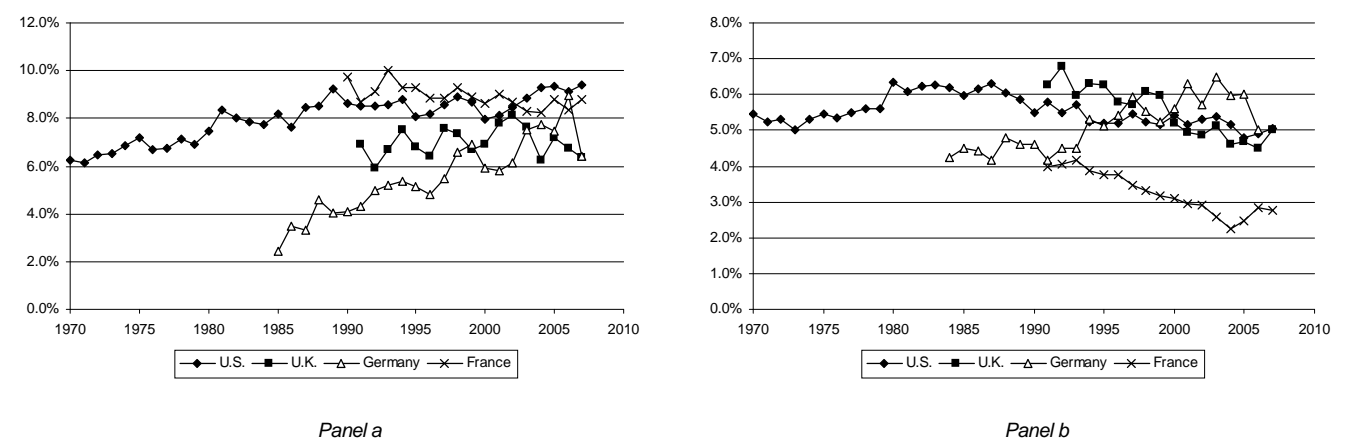

Figure 7: (a) Share of higher educated (college equivalent), and (b) share of lower educated (less than college) working in the financial sector (CPS, BHPS, SOEP, LFS) 


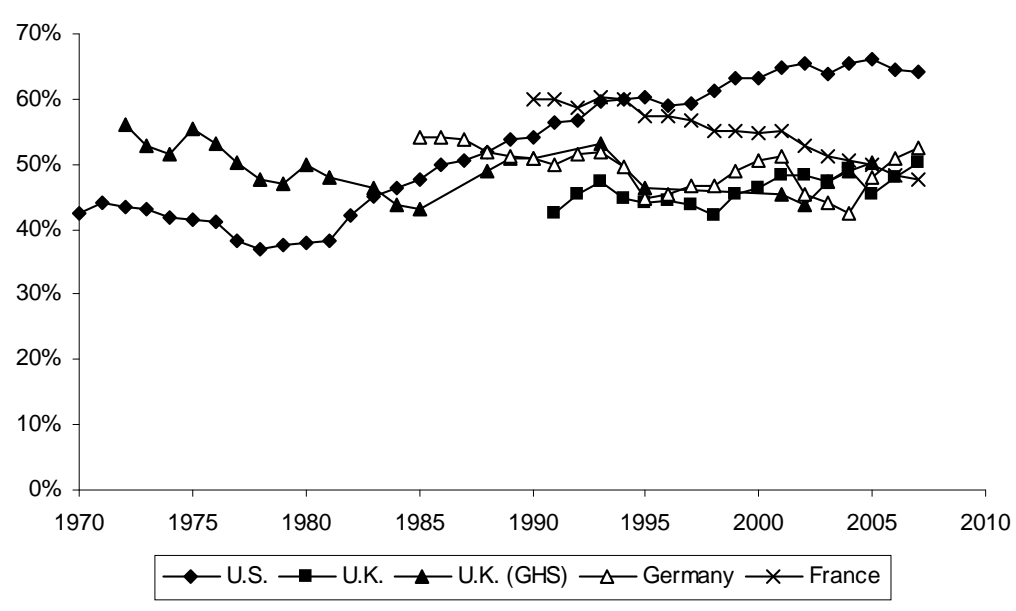

Figure 8: College/HS wage gaps (Wage regressions CPS, BHPS, GHS, SOEP, LFS)

is mixed. While finance dummies have come down somewhat, financial sector employment of skills has strongly increased, possibly putting upward pressure on wages of skilled individuals.

\subsection{Overall wage and employment structure}

Many studies have documented the rise in wage inequality in the U.S. and to some extent in the U.K. since the 1980s (see Introduction). Figure 8 shows the college/high school wage gap. ${ }^{21}$ In the U.S. the college/HS gap has increased substantially over time, although the relative supply of educated workers has been increasing, as well, since the 1970s. In contrast to the U.S., the development in France has been relatively flat to decreasing. This pattern is in line with other comparative studies on wage inequality (e.g. Piketty, 2007). In the U.K. the trend is rather increasing. And in Germany, the college premium has stayed relatively flat (in line with earlier studies on German inequality, but in contrast to recent results of Dustmann, Ludsteck, and Schönberg, 2009, who document a rising trend using new data).

Note the similarity between the development of the college/HS gap and the finance/nonfinance gap (compare Figure 6 and 8). Both gaps started to widen in the 1980s in the U.S., while they have been relatively stable in France over the past two decades. In the U.K. und in Germany the trend is less clear.

Comparing the development of the college/HS gap and financial booms / asset bubbles yields a final piece of suggestive evidence, by looking at (rough) indicators for extreme valuations of asset prices. Shiller (2000) introduced a very useful indicator for excessive stock market valuations. Building on the analysis of Benjamin Graham and David Dodd, he cal-

\footnotetext{
${ }^{21}$ The relative wages are estimated with cross-section log weekly earnings regressions on the education dummies using the same controls as for the estimation of the finance/non-finance wage gaps.
} 


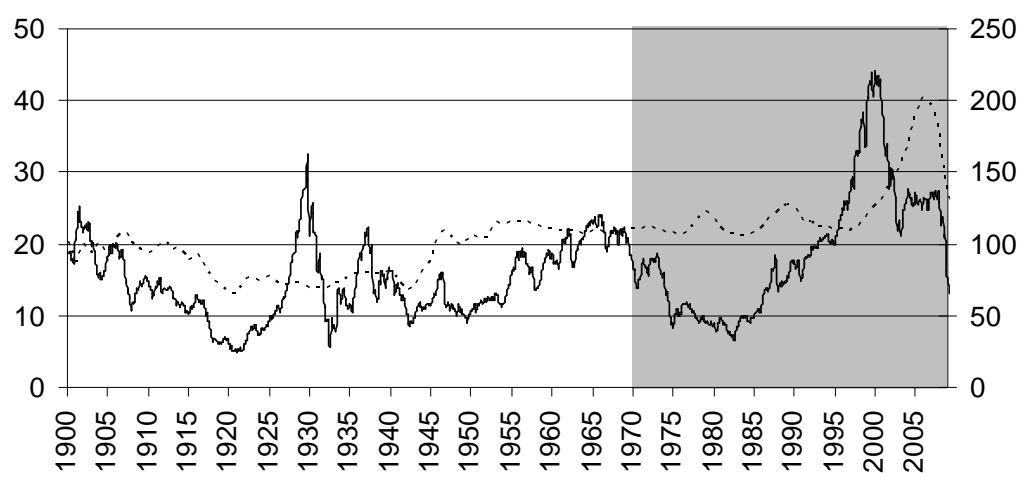

- 10-year PE ratio

...... Real home price index

Figure 9: 10-year U.S. historic price-earnings ratio and home price index (Homepage "Irrational Exuberance" Shiller)

culates the price-earning ratio (PE ratio) of the $\mathrm{S} \& \mathrm{P} 500$ using the 10-year moving average of historical earnings to provide a rough indication for how far stock prices have decoupled from fundamentals. Similarly, bubbles in housing can be approximated with a real house price index, also calculated by Shiller. ${ }^{22}$ Figure 9 plots the two indicators from 1900 to 2009 . One can see that the S\&P PE ratio reached a major peak during the stock market boom of 1929, which has only been surpassed during the recent dot-com bubble. More importantly, after having fallen during the 1970s, the measure started to rise in 1980s, and even after the burst of the dot-com bubble remained high. Furthermore, the extreme stock valuations during the dot-com bubble were subsequently replaced by a strong rise in home prices.

The comovements between college/HS wage gaps, finance wage gaps, measures of asset bubbles, and the timing of financial deregulation in the U.S. since the 1970s are striking. This contrasts to France, which has not experienced a comparable boom in the financial sector, and whose wage structure has remained much more static. In the U.K. and Germany the trends are less clear. The empirical findings thus are suggestive evidence for our theoretical framework, suggesting that asset bubbles and deregulation in the financial sector starting in the Reagan era have been important factors contributing to the rise in wage inequality in the U.S. and the divergence from countries like France.

\section{Conclusion}

Modern financial markets are characterized by high fees in nontraditional financial products, recurring phases of extreme valuations, and large rents to be earned in the financial sector; and that these features have played an important role in the recent developments of the wage struc-

\footnotetext{
${ }^{22}$ See http://www.irrationalexuberance.com/
} 
ture. This paper motivated and developed a theory where financial institutions benefit from deregulation and extreme asset valuations, yet the complexity and novelty of fundamentals surrounding asset bubbles and new financial products favor the supremacy of skilled individuals in exploiting these opportunities. As a result, the emergence of asset bubbles increases the opportunity set of skilled individuals in financial intermediation, raising wage inequality and financial sector employment of skilled labor. The rise is reinforced by financial deregulation, and in an international context, countries with a comparative advantage in financial intermediation experience a steeper rise. Furthermore, wages in finance may decouple from wages in other sectors if insiders are able to protect rents in financial intermediation from outsiders or tastes in careers differ across individuals.

The main theoretical results can, in principle, also be interpreted in a more general context of a "new economy" versus an "old economy". The difficulty to assess fundamentals and measure marginal productivities in a growing new economy (such as dot-com, consulting, and other more service oriented, less tangible sectors) creates increasing rent opportunities which skilled individuals are more adept in exploiting. Hence, a growing number of skilled individuals migrates from traditional to the new sectors, pushing up wages of skilled individuals.

An another aspect which the paper is silent about is the impact of the "brain drain" in the real sector caused by the rents in the financial sector on innovation and long-run growth in the economy. The model in this paper could be extended to include an R\&D sector generating new capital goods which is skill-intensive. Periods of financial booms would absorb R\&D resources, lowering technical progress, and thus would have a long-run impact on economic development.

The wage and employment patterns documented in the empirical part of the paper, although not being conclusive proofs, are highly suggestive for our theoretical results. Finance/nonfinance wage gaps have been increasing in the U.S. und the U.K., which both benefited from opportunities in global finance triggered by deregulations and extreme asset valuations. In countries with smaller financial sectors such as France and Germany, no such trends in finance wage gaps can be discerned. 


\section{References}

[1] Abreu, Dilip and Markus Brunnermeier (2003), "Bubbles and Crashes," Econometrica 71 (1), $173-204$

[2] Acemoglu, Daron (1998), "Why Do New Technologies Complement Skills? Directed Technical Change and Wage Inequality," Quarterly Journal of Economics 113, 1055-1090.

[3] Acemoglu, Daron (2002), "Directed Technical Change," Review of Economic Studies 69, 781-809.

[4] Acemoglu, Daron and Fabrizio Zilibotti (2001), "Productivity Differences," Quarterly Journal of Economics 116, 563-606.

[5] Autor, David, Lawrence Katz, and Melissa Kearney (2008), "Trends in U.S. Wage Inequality: Revising the Revisionists," Review of Economics and Statistics 90, 300-323.

[6] Autor, David, Lawrence Katz, and Alan Krueger (1998), "Computing Inequality: Have Computers Changed the Labor Market?," Quarterly Journal of Economics 113(4), 1169-1213.

[7] Barth, James, Gerard Caprio Jr., and Ross Levine (2008), "Bank Regulations are Changing: For Better or Worse?," Comparative Economic Studies 50, 537-563.

[8] Buchinsky, Moshe and Ben Polak (1993), "The Emergence of a National Capital Market in England, 1710-1880," Journal of Economic History 53, 1-24.

[9] Bencivenga, Valerie and Bruce Smith (1991), "Financial Intermediation and Endogenous Growth," Review of Economic Studies 58, 195-209.

[10] Blanchard, Olivier and Mark Watson (1982), "Bubbles, Rational Expectations and Financial Markets," in Paul Wachtel, Crises in the Economic and Financial Structure, Lexington Books, 295-316.

[11] Caballero, Ricardo, Emmanuel Fahri, and Mohamad Hammour (2006), "Speculative Growth: Hints from the U.S. Economy," American Economic Review 96, 1159-1191.

[12] Cahuc, Pierre and Edouard Challe (2009), "Produce or Speculate? Asset Bubbles, Occupational Choice, and Efficiency," IZA Discussion Paper 4630.

[13] Card, David (1996), "The Effect of Unions on the Structure of Wages: A Longitudinal Analysis," Econometrica 64 (4), 957-979.

[14] DiNardo, John, Nicole Fortin, and Thomas Lemieux (1996). "Labor Market Institutions and The Distribution of Wages, 1973-1992: A Semi-Parametric Approach," Econometrica 64 (5), 1001-1044.

[15] Dustmann, Christian, Johannes Ludsteck, and Uta Schönberg (2009). "Revisiting the German Wage Structure," Quarterly Journal of Economics 124, 843-881. 
[16] Feenstra, Robert C. and Gordon Hanson (1996), "Globalization, Outsourcing, and Wage Inequality," American Economic Review Papers and Proceedings 86, 240-245.

[17] Greenwood, Jeremy and Boyan Jovanovic (1990), "Financial Development, Growth, and the Distribution of Income," Journal of Political Economy 98, 1076-1107.

[18] Katz, Lawrence and Kevin Murphy (1992), "Changes in Relative Wages, 1963-1987: Supply and Demand Factors," Quarterly Journal of Economics 107, 35-78.

[19] Katz, Lawrence and David Autor (1999), "Changes in the Wage Structure and Earnings Inequality," in Orley Ashenfelter and David Card, Handbook of Labor Economics, Vol. 3A, Amsterdam: Elsevier Science, North-Holland, 1463-1555.

[20] Kindleberger, Charles P. (1996), "Maniacs, Panics, and Crashes," 3rd edition, New York: John Wiley \& Sons, Inc.

[21] Murphy, Kevin, Andrei Shleifer and Robert Vishny (1991), "The Allocation of Talent: Implications for Growth,” Journal of Political Economy 106, 503-530.

[22] Philippon, Thomas (2008), "The Evolution of the US Financial Industry from 1860 to 2007," mimeo, New York University.

[23] Philippon, Thomas and Ariell Reshef (2008), "Wages and Human Capital in the U.S. Financial Industry: 1909-2006," mimeo, New York University and University of Virginia.

[24] Piketty, Thomas (2007), "Top Incomes over the Twentieth Century : A Summary of Main Findings," in Top Incomes over the Twentieth Century, Oxford: Oxford university press, 1-17.

[25] Piketty, Thomas and Emmanuel Saez (2003) "Income Inequality in the United States, 1913-1998," Quarterly Journal of Economics 118(1), 1-39.

[26] Roine, Jesper, Jonas Vlachos, and Daniel Waldenström (2009), "The Long-Run Determinants of Inequality: What can we learn from top income data?," Journal of Public Economics, forthcoming.

[27] Santos, Manuel S. and Michael Woodford (1997), "Rational Asset Pricing Bubbles," Econometrica $65,19-57$.

[28] Shiller, Robert (2000), "Irrational Exuberance," Princeton, New Jersey: Princeton University Press.

[29] Tirole, Jean (1985), "Asset Bubbles and Overlapping Generations," Econometrica 53, 1499-1528.

[30] Weil, Philippe (1987), "Confidence and the Real Value of Money in an Overlapping Generations Economy," Quarterly Journal of Economics 102, 1-22. 
[31] White, Eugene (1990), "The Stock Market Boom and Crash of 1929 Revisited," Journal of Economic Perspectives 4(2), 67-83. 


\section{Appendix}

A. Welfare, dynamic efficiency, and bubbles This exposition follows Blanchard and Fischer (Lectures on Macroeconomics, 1989). Consider a central planner with a social welfare function,

$$
U=(1+g)^{-1} \beta \ln \left(A_{0} c_{2,0}\right)+\sum_{t=0}^{\infty}(1+g)^{t}\left[\ln \left(A_{t} c_{1, t}\right)+\beta \ln \left(A_{t+1} c_{2, t+1}\right)\right]
$$

weighing generations proportionally to technical progress, with $c_{1, t}$ and $c_{2, t}$ denoting consumption per efficiency units (let's abstract from skilled and unskilled for the moment). The resource constraint on the planner is given by

$$
\begin{aligned}
N_{t} k_{t}+y_{t} & =N_{t+1}(1+g) k_{t+1}+c_{1, t}+c_{2, t}, \text { with } \\
y_{t} & =\alpha^{-1} N_{t}^{\theta \alpha} k_{t}^{\alpha}\left(u-(\phi L)^{-1} N_{t}\right)^{\gamma}(1-u)^{1-\alpha-\gamma}
\end{aligned}
$$

First-order conditions with regards to $c_{2, t}, k_{t}$, and $N_{t}$, respectively, are

$$
\begin{aligned}
c_{2, t} & : \beta \frac{1}{c_{2, t}}-(1+g) \frac{1}{c_{1, t}}=0, \\
k_{t} & :-\frac{1}{c_{1, t-1}} N_{t}+(1+g) \frac{1}{c_{1, t}}\left[N_{t}+\frac{\alpha y_{t}}{k_{t}}\right]=0, \\
N_{t} & : \quad-\frac{1}{c_{1, t-1}} k_{t}+(1+g) \frac{1}{c_{1, t}}\left[k_{t}+\frac{\theta \alpha y_{t}}{N_{t}}-\frac{\gamma y_{t}}{\phi L u-N_{t}}\right]=0,
\end{aligned}
$$

The steady state is characterized by $c_{1, t-1}=c_{1, t}=c_{1}^{*}$. Not surprisingly, $N^{*}$, the optimum range of goods intermediated, is larger that in the decentral equilibrium, cf. expression (11):

$$
N^{*}=\frac{\phi(\theta-1) \alpha u L}{\gamma+(\theta-1) \alpha} .
$$

The economy is dynamically inefficient if

$$
k>k^{*}=\frac{\alpha y^{*}}{N^{*} g}
$$

Let's compare this golden-rule to the condition under which bubbles may arise in the decentral equilibrium,

$$
\bar{k}>\hat{k}=\frac{\alpha \hat{y}}{\theta N(g-\psi+g \psi)} .
$$

Traditional financial intermediation lowers the range of capital goods used by the real sector, $N<N^{*}$, lowering output per variety, $y / N$. For a given $N$, markups in traditional intermediation, $\theta$, lower the hurdle level. Hence, bubbles may arise although the economy appears to be dynamically efficient (using gross rates of return) if markups are high. On the other hand, rents in bubble intermediation, $\psi$, raise the hurdle, making bubbles less likely to occur. Overall, bubbles may increase dynamic efficienty, in line with the standard OLG model, however, the resulting rent opportunities may lower efficiency given the drain of skills in real production. 
B. Cycles of bubbles and inequality Consider two extensions to our basic framework. First, the aggregate bubble might burst with an exogenous probability $(1-q)$ next period. Second, skilled individuals are able to create new bubbles. The extended framework generates cycles of bubbles with elevated inequality.

Assume that the aggregate bubble might burst with exogenous probability $(1-q)$, see Weil (1987). Individual $i$ chooses investments, $\left\{k_{t}^{i}, b_{t}^{i}\right\}$, maximizing expected utility,

$$
\begin{gathered}
\ln c_{1, t}^{i}+\beta\left\{q \ln c_{2, b, t+1}^{i}+(1-q) \ln c_{2, n b, t+1}^{i}\right\}, \text { subject to } \\
c_{1, t}^{i}+k_{t+1}^{i}+b_{t}^{i} \leq w_{t}^{i}, \quad c_{2, b, t+1}^{i} \leq\left(1+r_{t+1}\right) k_{t+1}^{i}+\left(1+\xi_{t+1}\right) b_{t}^{i}, \quad \text { and } \quad c_{2, n b, t+1}^{i} \leq\left(1+r_{t+1}\right) k_{t+1}^{i},
\end{gathered}
$$

where the subscripts $b$ and $n b$ denote the state with bubbles intact and bubbles burst, respectively, and $1+\xi_{t+1} \equiv(1-\psi) B_{t+1} / B_{t}$ the growth factor of the bubble net of intermediation fees. First-order conditions (FOCs) are

$$
\begin{array}{rll}
k_{t+1}^{i} & : & -\left(c_{1, t}^{i}\right)^{-1}+\beta\left(1+r_{t+1}\right)\left\{q\left(c_{2, b, t+1}^{i}\right)^{-1}+(1-q)\left(c_{2, n b, t+1}^{i}\right)^{-1}\right\}=0, \\
b_{t}^{i} & : \quad-\left(c_{1, t}^{i}\right)^{-1}+\beta\left(1+\xi_{t+1}\right)\left\{q\left(c_{2, b, t+1}^{i}\right)^{-1}\right\}=0 .
\end{array}
$$

Using the FOCs one can show that the aggregate bubbles must grow according to the following no-arbitrage condition:

$$
1+\xi_{t+1}=\frac{(1+g)(1-\psi) b_{t+1}}{b_{t}}=\frac{\left(1+r_{t+1}\right) N(1+g) k_{t+1}}{q N(1+g) k_{t+1}-(1-q) b_{t}},
$$

and that, additionally using budget constraints, the aggregate demand for capital and bubbles per efficiency units is given by

$$
\begin{aligned}
N(1+g) k_{t+1} & =\frac{(1-q)\left(1+\xi_{t+1}\right)}{\xi_{t+1}-r_{t+1}} \frac{\beta}{1+\beta} \frac{u w_{t}^{u}+(1-u) w_{t}^{h}}{A_{t}} \\
b_{t} & =\frac{\xi_{t+1}-r_{t+1}-(1-q)\left(1+\xi_{t+1}\right)}{\xi_{t+1}-r_{t+1}} \frac{\beta}{1+\beta} \frac{u w_{t}^{u}+(1-u) w_{t}^{h}}{A_{t}}
\end{aligned}
$$

The bubble cannot grow faster than the growth rate of the economy in the long run as there would be a positive probability that the bubble outgrows the economy in finite time, $\lim _{t \rightarrow \infty}(1+$ $\left.\xi_{t+1}\right) \leq(1+g)$. Given risk aversion, a bubbly equilibrium thus exists if and only if

$$
q(1+g)(1-\psi)>\left(1+\hat{r}^{F} / \theta\right)
$$

The expected growth factor of the bubble net of intermediation fees must be strictly larger than the interest factor in the bubbleless steady-state. Hence bubbles cannot be too risky, see Weil (1987).

Given conditions under which bubbles might arise, bubbles can be created by skilled workers with technology

$$
\Delta B_{t}=F\left(B_{t-1}, K_{t}\right) H_{t}^{B},
$$


with the function $F: \mathbb{R}_{+}^{2} \rightarrow \mathbb{R}_{+}$being linearly homogeneous. A skilled individual can create an intrinsically worthless paper asset with an initial value proportional to the existing size of bubbles and capital in the economy. Imagine that like during the dot-com bubble era of the late 1990s, university graduates can set up and sell new (e.g. internet-based) companies that have never produced tangible revenues. Skilled individuals pursue these opportunities if the payoffs are greater than wages in real production (and intermediation of bubbles),

$$
F\left(\frac{b_{t-1}}{1+g}, k_{t}\right)>\frac{\left(\psi b_{t} / y_{t}+(1-\alpha-\gamma)\right) y_{t}}{(1-u) L}
$$

In this case, aggregate bubbles (per efficiency unit) grow according to

$$
b_{t}=F\left(\frac{b_{t-1}}{1+g}, k_{t}\right) h_{t}^{B}+\frac{\left(1+\xi_{t}\right)}{(1+g)(1-\psi)} b_{t-1},
$$

as new bubbles are created each period, until bubble creation is no longer attractive, or the aggregate bubble reaches the ceiling of the asymptotic bubbly path. ${ }^{23}$

Assume that the economy starts at $t=1$ without bubbles, $b_{0}=0$, conditions for bubbles prevail, and bubble creation is sufficiently attractive,

$$
F\left(0, k_{1}\right)>\frac{(1-\alpha-\gamma) y_{1}}{(1-u) L}
$$

For example, deregulation could shift up the function $F$ such that bubble creation becomes attractive. Hence, wages of skilled individuals adjust upwards in order to equalize rewards across bubble creation, bubble intermediation, and real production,

$$
w_{t}^{h}=F\left(B_{t-1}, K_{t}\right)=\frac{\psi B_{t}}{H_{t}^{F}}=\frac{(1-\alpha-\gamma) Y_{t}}{H_{t}^{Y}},
$$

and labor markets clear, $H=H_{t}^{B}+H_{t}^{F}+H_{t}^{Y}$. Bubbles are created until it is no longer attractive (before they reach the upper bound). Wage inequality remains at elevated levels until the bubble bursts. Depending on the functional form of $F$, inequality retreats following the crash, only to be rising again in the next phase of bubble creation.

In an economy characterized by high savings and low interest rates, there is a high demand for new investment opportunities. Smart individuals might exploit this demand by creating new investment opportunities, such as the latest dot-com start-up or CDO squared, especially if opportunities in the "real economy" are not sufficiently attractive. In such an environment, one bubble might chase the next, keeping wage inequality at elevated levels.

\section{Data and construction}

\footnotetext{
${ }^{23}$ Creation of bubbles in excess of the upper bound on the aggregate bubble would render all existing bubbles worthless, and thus is not worthwile to pursue. However, one best assumes that bubble creation becomes sufficiently difficult before we reach the upper bound such that it becomes unattractive, in order to have a well-defined equilibrium (with no incentives to deviate for single skilled individuals).
} 


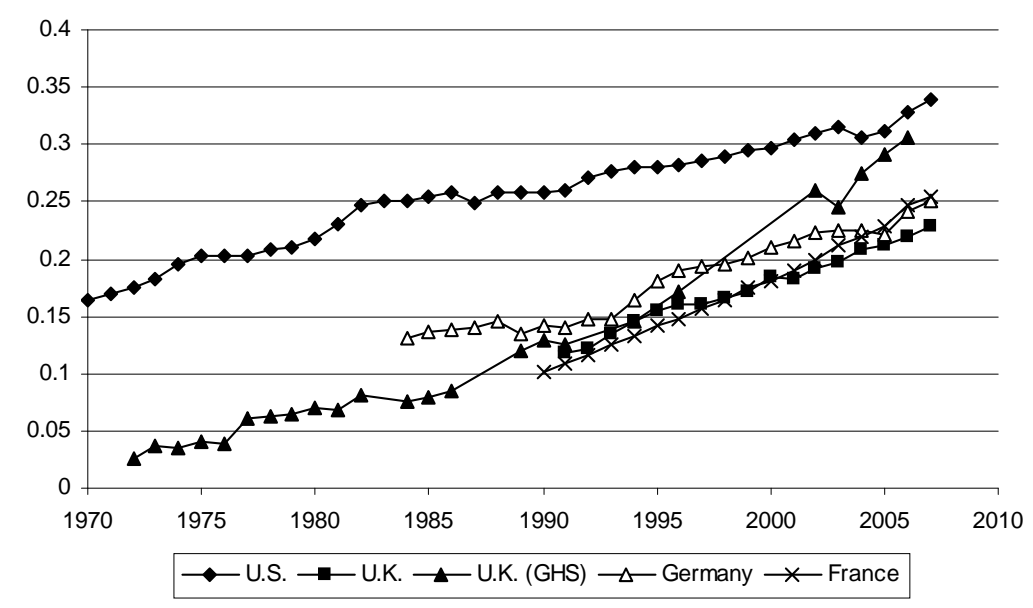

Figure 10: Share of higher educated (college equivalent) in workforce (CPS, BHPS, GHS, SOEP, LFS)

\subsection{Data sources and construction}

The wage and employment data comes from a variety of surveys such as the Current Population Survey (CPS) in the U.S. Processing of the CPS data set will serve as benchmark, with data from other countries processed as similarly as possible. See Appendix C for more details on data and construction.

Note that quality of data and documentation varies across countries. After proper selection, CPS and LFS (France) contain around 30'000 or more observations for each year, whereas the other countries have substantially less (around 5'000 observations). Independently of data issues, since systems of education vary substantially across countries, we focus on college graduates versus lower educational achievements which is most similar across country (see Figure 10). In wage regressions we use a similar granularity for controlling education across countries.

U.S.: The March Current Population Survey is used, covering 1970-2008. The basic processing closely follows Autor, Katz and Kearney (2008; see their data appendix): Samples include wage/salary workers aged 16 to 64 , working full-time (35+ hours), full-year (40+ weeks), not working in agriculture, public administration, or armed forces. Furthermore, weekly earnings below $50 \%$ of minimum wage threshold are dropped. Top-coded earnings are multiplied by 1.5 in line with Katz and Murphy (1992). CPS sampling weights are used. The generation of educational dummies and potential experience follows Autor, Katz and Kearney. Finally, the financial sector dummy includes finance (including banking, savings institutions, credit, securities, commodities, funds, trusts) and insurance. Patterns using hourly wages are very similar to patterns using weekly wages (both calculated from annual wage information 


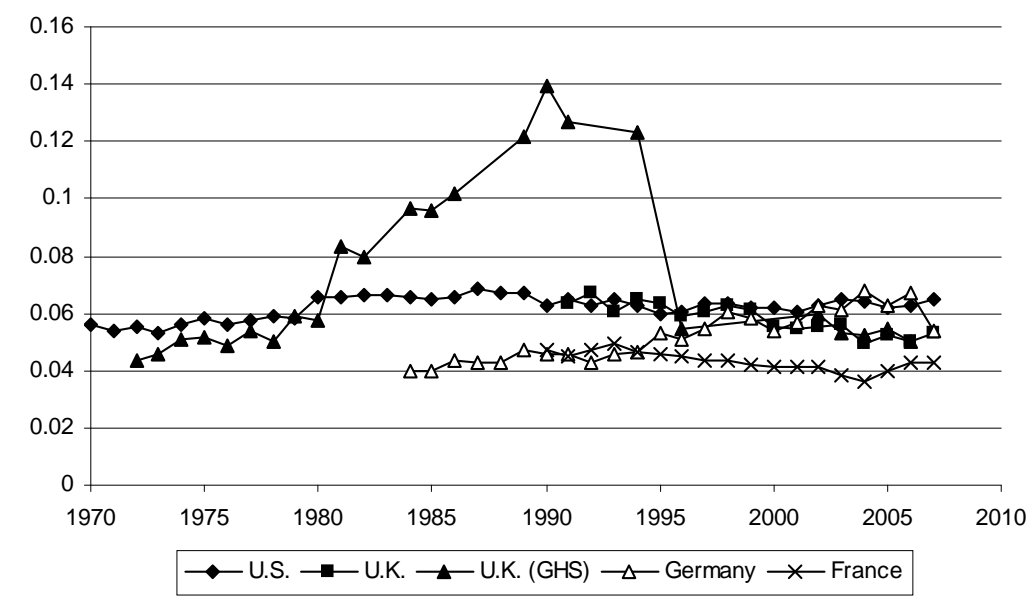

Figure 11: Share of workforce employed in financial intermediation (Wage regressions CPS, BHPS, GHS, SOEP, LFS)

using information on weeks and hours worked), hence weekly wages are used given substantial number of missing values in hours worked.

U.K.: The British Household Panel Survey (BHPS) is used, covering 1991-2007, as well as the General Household Survey (GHS), covering 1971-2006. We use two data sources since the quality of BHPS data is higher, yet GHS has longer time series. Selection in both data sets is similar to CPS. Hourly wages are used as patterns differ between weekly and hourly wages in both data sets, and hourly wages correct for overtime. There are several gaps in GHS due to missing industry classification. Generally, the industry classification of GHS needs to be regarded with caution as classifications changes in some years and old classification cannot be readily translated into new classification (see Figure 11 which initially shows huge rise in share of workforce employed in financial sector which drops in 1996). For early years, a similar fraction of the lowest wages are dropped as for CPS, and for later years (starting in 1999) national minimum wages are used.

Germany: The Socioeconomic Household Panel is used, covering 1984-2008, focusing on West Germany in line with other studies (e.g. Dustmann, Ludsteck, and Schönberg, 2009). Selection is similar to CPS. Hourly wages are used. As no national minimum wage exists (sector-specific minimum wages), a similar fraction of the lowest wages are dropped as for CPS.

France: The Labor Force Survey (enquête emploi) is used, covering 1990-2007. Selection is similar to CPS. Hourly wages are used. Full minimum wage used as cut-off leading to similar fraction of observations dropped as for CPS. 